\title{
PENSAR E RESISTIR: UM CONVITE À REFLEXÃO EM TEMPOS DE CRISE
}

Editorial

\author{
Javier Ignacio Vernal \\ Doutor em Filosofia pela Universidade \\ Federal de Santa Catarina. \\ Editor da revista INTERthesis, \\ Universidade Federal de Santa \\ Catarina, Florianópolis, Brasil \\ jivernal@gmail.com \\ http://orcid.org/0000-0003-4014-6656 \\ Emilly Joyce Oliveira Lopes Silva \\ Doutora em Ciências Humanas pela \\ Universidade Federal de Santa Catarina. \\ Editora Assistente da revista INTERthesis, \\ Universidade Federal de Santa \\ Catarina, Florianópolis, Brasil \\ emillyoliveiralopes@gmail.com \\ http://orcid.org/0000-0001-5246-7647
}

Raíssa Jeanine Nothaft Doutora em Ciências Humanas pela Universidade Federal de Santa Catarina. Editora Assistente da revista INTERthesis, Universidade Federal de Santa Catarina, Florianópolis, Brasil raissajnothaft@gmail.com http://orcid.org/0000-0002-3933-0379 (D)

A virada de 2020 para 2021 foi, na história recente, uma experiência particular. Poucos conseguiram festejar como nos anos anteriores, uma vez que continuamos experimentando as incertezas e restrições iniciadas com a pandemia de Covid-19 no Brasil, e agravadas pela política negacionista e genocida nacional. Já na despedida do ano de 2019, tentávamos deixar para trás a destruição da Amazônia e as práticas anticientíficas do governo federal, mas nada indicava que o ano de 2020 seria ainda mais crítico. Exemplo disso é o Relatório do Human Rights Watch, que afirma que "o presidente Jair Bolsonaro tentou sabotar medidas de saúde pública destinadas a conter a propagação da pandemia de Covid-19", algo que nem mesmo o pessimismo cotidiano poderia nos fazer esperar. ${ }^{1}$

Apesar disso, hoje, felizmente, podemos dizer que a ciência brasileira venceu a ignorância orgulhosamente demonstrada pelo presidente e seus funcionários próximos.

${ }^{1}$ Disponível em: https://www.hrw.org/pt/world-report/2021/country-chapters/377397 (acesso em 26 fev. 2021). 
Depois de quase um ano em que assistimos às mais descabidas, e talvez criminosas, alocuções do executivo, e após alcançarmos o triste número de mais de 200.000 pessoas mortas no Brasil ${ }^{2}$ por causa da pandemia de Covid-19, as vacinas desenvolvidas em dois centros de pesquisa brasileiros, em parceria com instituições estrangeiras, começaram a ser aplicadas no país. Tal virada possibilitou que a ciência fosse fortalecida, assim como evidenciou o papel que a interdisciplinaridade tem também em situações extremas.

Nesse cenário, a Revista INTERthesis ressalta a importância do conhecimento como forma de resistência, sobretudo na adoção de um pensamento pluralista e interdisciplinar, que promova percursos alternativos e arriscados. Entendemos que, como afirma Jack Halberstam, "disciplinas qualificam e desqualificam, legitimam e deslegitimam, recompensam e punem, e o mais importante, elas se reproduzem estaticamente e inibem dissidência" (HALBERSTAM, 2020, p. 31). Nessa perspectiva, vale dizer que as concepções de interdisciplinaridade são variadas, mas, existe consenso sobre algumas de suas características. A abordagem mais comum tende a compreendê-la como um processo de resolução de problemas complexos, uma integração de visões disciplinares diversas, construindo uma perspectiva mais abrangente. Indo um pouco além, alguns autores reivindicam que "a interdisciplinaridade reside na capacidade de integrar modos de pensar de várias disciplinas para produzir um avanço ou salto do conhecimento a um patamar que seria impossível de ascender por meios disciplinares" (LEIS, 2011, p. 107108).

Com essa reflexão, fica explícito que, diante da complexidade da crise sanitária e humanitária em que vivemos, a interdisciplinaridade desponta como caminho potente. Isso porque ela nos permite pensar e explorar alternativas que fogem das formulações e armadilhas binárias, sempre falaciosas, como no dilema, repetido até a exaustão pelo governo Bolsonaro, entre salvar vidas ou salvar a economia brasileira. Desse modo, as pesquisas interdisciplinares, num futuro próximo, dirão quais países tiveram consequências econômicas mais drásticas: os que implementaram medidas para conter a transmissão da doença, ou aqueles que decidiram não fazer nada.

Proteger a vida dos brasileiros parece interessar menos ao governo que as chamadas pautas morais, ora entendidas como cortina de fumaça, ora como a principal linha política do governo de Jair Bolsonaro, que seguem impondo restrições à autonomia, ao desejo e à liberdade. Nesse contexto, esse editorial também inaugura as publicações

\footnotetext{
2 No dia 05 de março de 2021 o total de mortes por Covid1-19 no Brasil totalizava 260.970 pessoas.
} 
do Dossiê temático "(Re)discutindo sexualidade: corpo, prazer e desejo em tempos conservadores", que teve sua chamada lançada em 2020. A discussão não poderia ser mais atual diante dos retrocessos que estamos vivendo, como, por exemplo, no recente discurso de Damares Alves e Ernesto Araújo na ONU, que reforçou internacionalmente a imagem retrógrada da agenda política brasileira (KWEITEL; ASSANO, 2021).

Ademais, segundo o Relatório de 2019 do Grupo Gay da Bahia, a cada 26 horas uma pessoa LGBT + é assassinada ou se suicida vítima da LGBTfobia, fato que coloca o Brasil em primeiro lugar em relação aos crimes contra a população LGBT+. ${ }^{3}$ Dados de 2020 (ANTRA, 2021) revelam que "o Brasil assegurou para si o $1^{10}$ lugar no ranking dos assassinatos de pessoas trans no mundo" (p. 7). Além disso, a associação estima que cerca de $70 \%$ da população de travestis e mulheres transexuais não conseguiram acesso às políticas emergenciais do Estado. Por isso, muitas delas, trabalhadoras sexuais, se viram obrigadas a se expor ao vírus em todas as fases da pandemia, a fim de manter sua subsistência. Corroborando esses dados, a pesquisa LGBT+ na pandemia ${ }^{4}$, identificou as pessoas transgênero como as mais vulneráveis aos impactos da crise sanitária, seguidas por pessoas pretas, pardas e indígenas.

A despeito desses números, o Ministério da Mulher, Família e Direitos Humanos gastou apenas $53 \%$ do seu orçamento em 2020 . Desse valor, $0 \%$ foi endereçado a políticas para pessoas LGBT+e $12 \%$ foram endereçados às políticas para mulheres, dos quais menos de $3 \%$ foram efetivamente gastos 5 . Destacamos ainda que o investimento em enfrentamento da violência contra mulheres diminuiu drasticamente em 2020, mesmo ano em que vimos os casos de feminicídio aumentarem em pelo menos $2 \%$ (FBSP, 2020).

Tais aspectos da realidade apontam para uma reação conservadora, de caráter transnacional, aos ganhos políticos e sociais que alguns grupos obtiveram nas últimas décadas. De acordo com Biroli, Machado e Vagione (2019, p. 27):

o uso do conceito neoconservador permite identificar as principais mutações e matrizes que caracterizam as ações reativas e

${ }^{3}$ Disponível em: https://grupogaydabahia.com.br/relatorios-anuais-de-morte-de-lgbti/ (acesso em 26 fev. 2021).

${ }^{4}$ Disponível em:

https://static1.squarespace.com/static/5b310b91af2096e89a5bc1f5/t/5ef78351fb8ae15cc0e0b5a3/15932794 20604/\%5Bvote+lgbt+\%2B+box1824\%5D+diagno\%CC\%81stico+LGBT\%2B+na+pandemia completo.pdf (acesso em 26 fev. 2021).

${ }^{5}$ Disponível em: http://www.generonumero.media/orcamento-damares-2020-mulheres-lgbt/ (acesso em 26 fev. 2021). 
contemporâneas de setores religiosos diante das mudanças nas formas de regular a ordem sexual. (...) Conquistas importantes na esfera legal de várias sociedades, como a extensão da permissão para o aborto, 0 reconhecimento do casamento entre pessoas do mesmo sexo e a aprovação das leis de identidade de gênero, tiveram como consequência não intencional o surgimento de estratégias, discursos e atores renovados no campo conservador.

Essas estratégias, discursos e atores, contudo, não se limitam ao campo da sexualidade e das questões de gênero, lançando-se também em cruzada contra a ciência, o pensamento crítico e qualquer forma de diversidade.

Diante dessas condições, o nosso posicionamento é pela resistência, bem como pela procura e divulgação de alternativas e possibilidades, pois acreditamos que o Brasil que habitamos pode ser diferente. A cada artigo publicado, seja no dossiê temático, seja nos demais eixos da revista, a INTERthesis acrescenta um novo tijolo nessa muralha contra o obscurantismo. Lembramos ainda que a pandemia nos enfrentou não somente com a possibilidade da perda do futuro, mas com uma ideia mais provocadora, a de que haveremos de perder o futuro se não o pensamos como algo que podemos perder (AHMED, 2019).

Por tudo isso, agradecemos ao conjunto de autoras/es, leitoras/es e avaliadoras/es que colaboram com a missão da INTERthesis. Juntos/as continuaremos contribuindo para a discussão de mundos possíveis e para o enfrentamento de estruturas obsoletas e opressivas.

\section{REFERÊNCIAS}

AHMED, Sara. La promesa de la felicidade. Una crítica cultural al imperativo de la alegría. Buenos Aires: Caja Negra, 2019.

BENEVIDES, Bruna G.; NOGUEIRA, Sayonara Naider Bonfim (Orgs.). Dossiê dos ASSASSINATOS e da violência contra TRAVESTIS e TRANSEXUAIS no Brasil em 2020. São Paulo: Expressão Popular, ANTRA, IBTE, 2021.

BIROLI, Flávia; MACHADO, Maria das Dores Campos; VAGGIONE, Juan Marco. Gênero, neoconservadorismo e democracia. São Paulo: Boitempo, 2020.

FBSP - FÓRUM BRASILEIRO DE SEGURANÇA PÚBLICA. Anuário Brasileiro de Segurança Pública 2020. São Paulo: FBSP, 2020. Disponível em: https://forumseguranca.org.br/wp-content/uploads/2021/02/anuario-2020-final-100221.pdf. Acesso em 26 fev. 2021. 
HALBERSTAM, Jack. A arte queer do fracasso. Recife: Companhia Editora de Pernambuco, 2020.

KWEITEL, Juana; ASANO, Camila. Na ONU, Brasil faz discurso descolado do resto do mundo. Folha de São Paulo, 22 fev. 2021. Disponível em:

https://www1.folha.uol.com.br/mundo/2021/02/na-onu-brasil-faz-discurso-descolado-doresto-do-mundo.shtml. Acesso em 26 fev. 2021.

LEIS, Hector Ricardo. Especificidades e desafios da interdisciplinaridade nas ciências humanas. In PHILIPPI, Arlindo; NETO, Antônio J. Silva. Interdisciplinaridade em ciência, tecnologia e inovação. Barueri: Editora Manole, 2011. 